\title{
A CASE STUDY OF MUNICIPAL SOLID WASTE MANAGEMENT IN NEPAL COMPARED TO THE SITUATION IN THE EUROPEAN UNION AND SWEDEN
}

\author{
Gustav Larsson \\ Jakob Sahlén \\ Lund University, Sweden \\ Lennart Mårtensson \\ Kristianstad University, Sweden \\ Sanjay Nath Khanal \\ Kathmandu University, Nepal
}

\begin{abstract}
Nepal, situated in the Himalayan belt has a rapidly growing population together with high urbanisation rate. These factors are currently causing problems connected to municipal solid waste (MSW). E.g. leakage of hazardous substances to soil and surrounding aquatic systems, spread of odour and naturally unfamiliar materials to natural biotopes, all of which generate environmental damage and health problems. There are certain differences in waste generation and waste composition between urban areas of Nepal. In order to retrieve a broad picture of the current waste management situation, three population differentiated municipalities in different areas of the country were investigated. Studies of the MSW regarding composition and generation were conducted. Moreover, waste management in Nepal was compared with the basic waste management in the European Union (EU) and Sweden. Landfill sites (LFS) in Ghorahi Municipality, Pokhara Sub-metropolitan City and Kathmandu Metropolitan City were studied. Our studies show differences in waste composition, generation and management between the three locations. The differences are somewhat interconnected with population size and tourism. Cities with higher population and more tourism tend to have a higher generation and more diverse MSW. Nevertheless, the urban areas of Nepal are very much in need of a more structured waste management system, a system more alike the waste management of EU. Apart from structural problems, there are attitude and behavioural issues that needs to be dealt with. Further studies regarding social patterns, attitude and behaviour, as well as the economic flow of MSW, needs to be conducted in order to retrieve an even broader picture and understand important underlying issues.
\end{abstract}

\section{KEYWORDS}

Solid waste, waste generation, waste composition

\section{INTRODUCTION}

Approximately half of the world population can be found in Asia. Moreover, more than half of the urban dwellers of the world also live in Asia. The significant projected population growth in Asia is expected to be accompanied by a massive urbanisation process. Currently, 
migration from rural to urban areas in Asia is already occurring at a significant pace. Urban areas in Asia have expanded and will have to expand with an enormous rate in order to fulfil the essential needs of the growing population [4]. The generation and composition of the MSW tends to differ in correlation with socio-economic factors connected to urban areas, e.g. prosperity level [3]. Therefore, progressive and feasible MSW management is essential when MSW is generated even faster and with a dissimilar composition than before.

Nepal, situated in the Himalayan belt, is often divided into three different big regions characterised by their terrain. The so called hilly landscape constitute the major area of Nepal, followed by the mountain region and the low-landed Terai in the south. The majority of the people live in the Terai and the hilly region [13]. Even though the population living in urban areas of Nepal is quite small compared with urban areas in other developing countries, the urbanisation process in Nepal is currently drastic and the population in these areas is rapidly increasing [13]. Along with rapid population and urban growth rates, problems connected to MSW are increasing. Nepal consists of 58 municipalities with varying population size and living standards. Thus, the produced MSW differs both in terms of quantity and quality within the country .

This paper will concentrate on describing the current waste management situation of Nepal compared with MSW management in the EU and in Sweden, and give recommendations for further development. The MSW composition and generation in connection to three population differentiated municipalities will be studied. Further information regarding location, population size, growth rates, earlier studies conducted, MSW collection and sorting, connected to the three sites can be found elsewhere [10].

\section{BACKGROUND}

\subsection{MSW Management in Nepal}

Regarding the MSW management of Nepal, in the urban areas there are certain trends that can be seen as common. The sorting of MSW for re-use, re-cycling and energy recovery; domestically, industrially, commercially and institutionally, is only conducted when economical incentives are clearly recognized. That is if the waste in particular has a value for selling and can be re-used, re-cycled or recovered for energy. Objects of value are e.g. paper, metals, glass and plastics $[14,15]$. Collectors bicycle around, on so called hawk cycles, from door to door in the cities in search for waste of value. The collectors can either be selfsufficient or connected to private scrap dealer's shops, so called Kawadi shops [14].

Additionally, so called scavengers scavenge transfer stations, LFS, the streets, municipal containers and various places where MSW is deposited. The scavengers then sell their findings to Kawadi shops, from where the MSW either is sold within or in the vicinity of the municipality, or, as the major part is; finally sold to industries in India [14]. Both in rural and urban areas of Nepal, incineration of waste that has no obvious value, occur both sporadically and frequently without any energy recovery. Burning piles of waste can be seen along roads and riversides. Furthermore, inaccurate depositing of waste occurs along the river banks and even in the rivers, causing hazardous health and environmental problems in-situ as well as downstream [13].

\subsection{MSW Management in the European Union}

The MSW management, the sorting, the collection and the treatment of wastes, differs a lot within EU; still there are general similarities which all originate from the transposition of EU 
directives down to national regulations. The Waste Framework Directive (Directive 2008/98/EC on Waste) was established 1975 and re-edited 2006 and 2008. The framework gives emphasis to the handling of waste expressing the importance of minimisation, the protection of the environment and human health, and requires each member state to establish and sustain waste management plans. In terms of waste handling, the framework especially gives emphasis to the waste hierarchy [7]. There are a number of subsequent directives, of which all are aligned with the principles of the waste hierarchy; reducing, re-using and recycling wastes before facilitating means to recover energy, and then finally disposal on LFS. The subsequent directives give focus to specific issues and waste streams, e.g. The Landfill Directive (99/31/EC), The Packaging and Packaging Waste Directive (94/62/EC), Directive on Incineration of Wastes (2000/76/EC) and The Integrated Pollution Prevention and Control Directive $(96 / 61 / \mathrm{EC})$ etc $[7,6]$.

Furthermore, EU has established policies and principles that are implemented or are being implemented into EU regulation [5]:

- The Principle of Prevention - 'to secure the conservation of nature and resources, waste generation must be minimized and avoided where possible (...)'

- The Precautionary Principle - 'to secure a reduction in the impacts from waste on human health and the environment, especially to reduce the hazardous substances in waste (...)'

- The Polluter Pays Principle - 'to make sure that those who generate waste or contaminate the environment should pay the full costs of their actions (...)'

- The Extended Producer Responsibility - promoting extended responsibility of the manufacturers of a product to the entire life-cycle of that product, hence facilitating sustainable improvements both up-stream and down-stream

- The Proximity Principle - try to re-use, re-cycle or recover for energy as close as possible from the generation place of the wastes by establishing '(...) adequate infrastructure' and 'by establishing an integrated and adequate network of disposal facilities (...)'

- The Subsidiary Principle - delegation of power to lower level of governance

In terms of waste generation per capita in EU, there are differences between and within countries. Socio-economic indicators like gross domestic product per capita, infant mortality rate, population density, tourist flows and unemployment rate, affect the generation of wastes. People that are categorized as having a very high prosperity level tend to generate more waste per capita. But regardless of prosperity level, people living in highly dense urban areas tend to generate more waste per capita then do people in rural or less dense urban areas [3].

\subsection{MSW Management in Sweden}

In Sweden the average waste generation per capita and day is about $1.4 \mathrm{~kg}$. The quantities of waste have increased over the last few years with approximately 3-4\% per year. During 2008, $97 \%$ of the household waste in Sweden was recovered and 3\% was deposited on LFS. This is a large reduction compared with previous years. Within the category of recovery material, recycling make account for around 35\%, incineration for energy recovery about $49 \%$ and biological treatment approximately $13 \%$. In $75 \%$ of the Swedish municipalities the collection of household waste is managed by external private companies and the remaining $25 \%$ by local authorities. The collecting is mainly door-to-door systems or from larger containers where people live in apartment blocks [2]. In Sweden the recycling of paper covers $74 \%$ of all papers, paper packaging and corrugated cardboard. Furthermore, 67\% of the metal packaging and $94 \%$ of the glass packaging was recycled in 2008 [2]. Waste incineration equals 
approximately $20 \%$ of the total produced district heating in the country. In accordance with the waste hierarchy of EU, in Sweden MSW is only deposited on LFS in cases where no other option of reuse, recycling or any other energy recovery is feasible. The LFS are strictly regulated according to national guidelines. Producers have a responsibility to collect their specific refuse from products (e.g. glass, cans, packaging etc), and the municipality has the responsibility to collect from households. Additionally, the households have the responsibility to separate paper and packaging, glass, metal, batteries, electric and electronic, and bulky waste [2]. In Sweden the number of municipal recycling centres is increasing. These centres handle the waste fractions like bulky waste that is too large to be handled in bags or in bins in the regular collection system. Most of the recycling centres are also taking care of hazardous, electric and electronic, and garden waste as well as demolition materials. The recycling centres are handling approximately $154 \mathrm{~kg}$ of waste per capita and year. According to the Swedish interest organisation, Avfall Sverige, almost half of the Swedish municipalities have a collection system for separated organic waste. The organic waste is either used for composting or for biogas production. The remaining municipalities collect the organic waste in the mixed waste fraction later to be incinerated for energy recovery [2].

\section{ALLOCATION AND DESCRIPTION OF THE LANDFILL SITES}

\subsection{Karaute Danda Sanitary Landfill Site - Ghorahi}

The LFS is situated in the vicinity of Ghorahi municipality in the district of Dang southwest in the Terai region of Nepal. More accurately, in ward 9 approximately $1 \mathrm{~km}$ outside of the urban area of Ghorahi. The total area of the LFS is 20 ha, of which 1 ha is used for MSW management and the remaining area for plantations of various trees and other vegetation. The area used for final disposal has recently been increased within the property. Moreover, on the property there is a sorting platform on which a unit of nine employees sorts the MSW into fractions of paper and plastics [9].

\subsection{Pokhara Landfill Site - Pokhara}

Pokhara LFS is allocated approximately $6 \mathrm{~km}$ outside of PSMC in ward 18 in the vicinity of Seti River. The LFS was constructed 1997-2003 and has been in operation since 2004. The total area of the LFS is 10 ha, of which 4 ha are utilised for final disposal of MSW. Composting and treatment area (reed bed, leachate collection ditch, leachate treatment plant) make up for 2.25 ha. Buffer zone, roads and other infrastructure account for the remaining 3.75 ha. The composting area is currently not in use. The constructed wetland area and reed beds function as nutrient and contaminant traps for the effluent leachate water [9].

\subsection{Sisdole Landfill Site - Kathmandu}

The landfill site was partly constructed under supervision, both technical and economical, by Japan International Co-operation Agency in December 2005. The purpose of the Sisdole LFS was to serve as short-term disposal site while other options were investigated. The life span of the LFS was planned for 2-3 years [9]. At Sisdole LFS waste from KMC and Lalitpur Submetropolitan City (LSMC) is handled [11]. The LFS covers a total area of 15 ha of which 2 ha is the actual landfill area. 13 ha of the area are occupied by protection and buffer zones, access and internal services roads, administration facilities and leachate treatment plant [9].

\section{METHODOLOGY}


Literary studies were conducted along with field studies and interviews in Nepal during May and June 2009. Field studies were made at the three different LFS and transfer stations along with visits at local municipality offices where interviews with people operating at the different sites were conducted.

For composition studies at LFS a method modified for utilisation in Nepal by Dinesh Raj Manandhar based on the standardised method by [12] at the University of Central Florida was used. The method was previously used in Nepal in compositions studies conducted by [1].

On every LFS, approximately $260 \mathrm{~kg}$ of waste was collected from random incoming vehicles. The MSW was then collected and mixed in order to receive a representative product. 2-3 reductions were conducted as described as follows . $1^{\text {st }}$ reduction; the whole sample collected was divided equally into four different piles, quadratic distributed on the ground upon which the two piles of one diagonal were removed. This procedure was carried out two or three times depending on the amount of the MSW collected $\left(2^{\text {nd }}\right.$ and $3^{\text {rd }}$ reduction). The remaining waste was then sorted according to the following fractions: Plastics, paper, glass, rubber and leather, textile, metal, construction/demolition waste and dust, organic, others (uncategorised wrapping paper etc.) The weight of each fraction was determined and the percentage of the total weight calculated.

During field studies interviews and notes were taken from staff members at the LFS concerning incoming vehicles loaded with MSW. The number of incoming vehicles and information about varying densities on MSW resulted in a quantification study. The information regarding densities was collected from [11]. Present population sizes were calculated from known and estimated populations and growth rates according to documents and information from local authorities.

\section{RESULTS}

\subsection{Composition analyses of municipal solid waste}

In Figure 1 the results from the composition study is presented. The highest amount of organic matter was found on Karaute Danda Sanitary LFS (65.8\%) followed by Sisdole LFS (61.9\%) and Pokhara LFS (49.1\%). Additionally, industrial and medical waste which should not end up on LFS was observed on all of the three LFS.

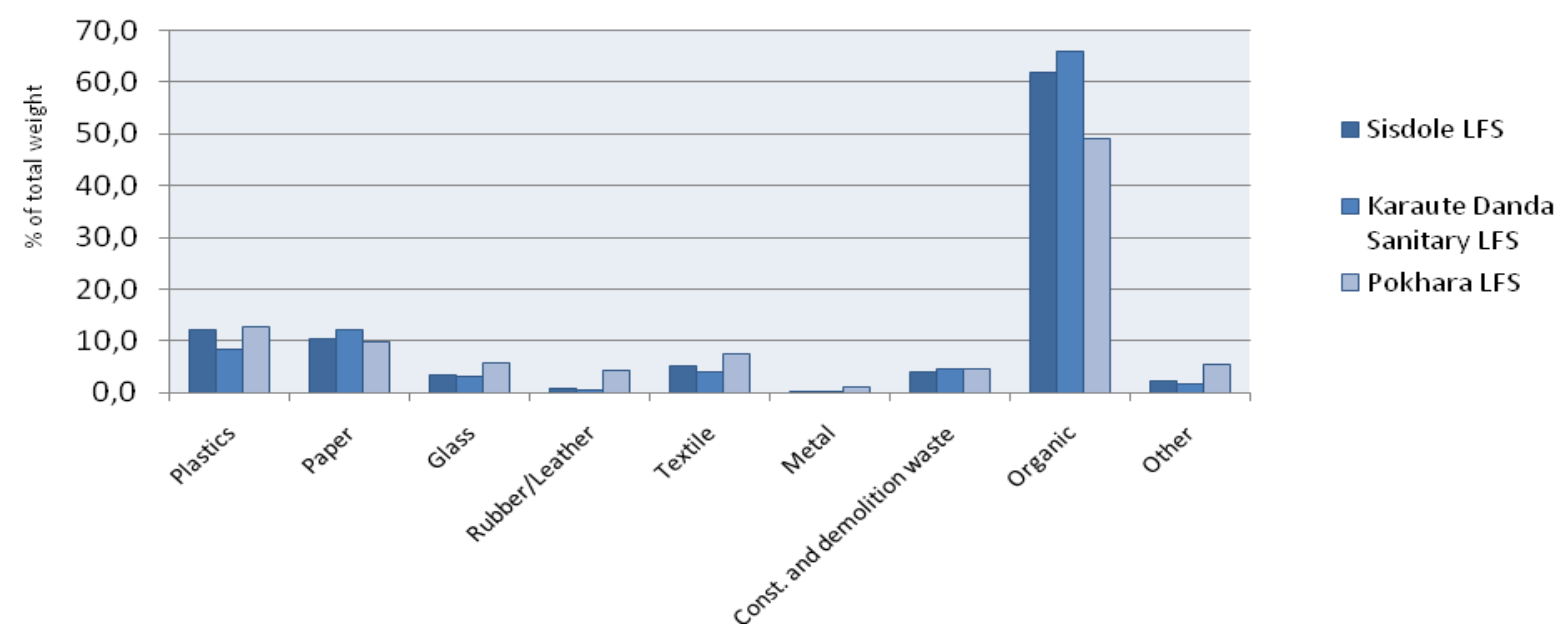

Figure 1. Results from the composition study from the three studied LFS. 


\subsection{Quantification}

Table 1 present the the total amount of waste generated in the the three municipalities respectively. The highest amount per capita was generated in Pokhara and the lowest in Ghorahi. The estimated population of Ghorahi Municipality, PSMC is based on an annual growth rate of approximately $4.0 \%$ and $5.1 \%$ respectively. The estimated populations of KMC (941 602) and LSMC (210 540) have been calculated with an annual growth rate of $4.6 \%$ and $3.5 \%$ correspondingly.

Table 1. Population, total waste generated and waste generated per capita for the three studied areas.

\begin{tabular}{llll}
\hline Parameters & $\begin{array}{l}\text { Ghorahi } \\
\text { Municipality }\end{array}$ & Pokhara SMC & $\begin{array}{l}\text { Kathmandu MC \& } \\
\text { Lalitpur SMC } \\
\text { Population (June 2009) }\end{array}$ \\
$\begin{array}{l}\text { Total waste generated (kg/day) } \\
\begin{array}{l}\text { Waste per capita (kg/person } \\
\text { and day) }\end{array}\end{array}$ & 6957 & 242668 & 1152142 \\
& 0.26 & 95279 & 392833 \\
\hline
\end{tabular}

\section{DISCUSSION}

In comparison with earlier MSW composition studies in Nepal, we see that our study from Ghorahi Municipality show similar results; organic matter $(65.8 \%)$. Nevertheless, we believe that the result from [8] regarding the amount of organic matter (79.1\%) perhaps is a bit too high and misleading while including not only urban but also rural wards outside of the LFS catchment area. Earlier studies show a marginal higher amount of total generated MSW in Ghorahi Municipality, including the whole population both urban and rural wards, than our study. Concerning PSMC, previous studies show very high amount of organic matter in MSW generated $(62 \%)$ in comparison with our result $(49.1 \%)$. In terms of per capita MSW generated in PSMC, both our and previous studies show relatively high but similar results. However, our study are study, based on collection from several wards, shows a more accurate result with lower amounts of organic.

Both our and previous results from KMC perhaps are the most difficult and complex among the observed municipalities to analyse. Many factors such as seasonal tourism flows and temporary solutions for MSW affect the MSW generation and its composition in the catchment area of the LFS. Therefore, our results should be looked upon as quite temporal. Nonetheless, previous studies show a higher amount of organic matter $(65 \%)$ than our study shows $(61.9 \%)$. Once again the methods of conducting the studies differ in data collection methods. Our study is based on MSW coming to the Sisdole LFS, while the previous study was based on household collection hence excluding the separation conducted at Teku transfer station.

As seen in the results above, there are some differences regarding the MSW composition between Ghorahi Municipality, PSMC and KMC. Before we received our results, we believed that trends concerning the population size and the degree of sorting would be somewhat negatively correlated; the bigger population, the lower amount of organic matter in the MSW put on LFS and hence a lower degree of sorting. But we saw that KMC had a higher amount of organic matter than expected, hence the sorting degree was also higher than expected. 
PSMC instead had the lowest degree of sorting and therefore also the lowest amount of organic matter in the MSW. Ghorahi Municipality had the highest degree of sorting. We believe that differences such as seasonal tourism flows, living standards, economic situation and population growth between the observed municipalities reflects on the composition, total and per capita generation of the MSW.

In Ghorahi the size of the LFS was more adapted to the actual population and total amount of MSW generated. According to [16], the Municipality of Ghorahi prioritises MSW management among the highest issues of the municipality, even prior to water supply. KMC on the other hand, with Sisdole LFS currently operating above full capacity, was not at all adapted to the total MSW generated in the specific catchment area. When it comes to PSMC we believe that the main reason why the degree of sorting is that low, is first because of the very high and recently fast population growth and secondly combined with the fact that the catchment area has a high tourism density. The two factors mentioned, we believe facilitate a higher demand for more diverse product spectrum initially from the tourists themselves but because of an economic growth in the region, also from the local citizens. Simply, the more diverse the product spectrum is the more intense and diverse the MSW generated will be.

In regards to the three different LFS observed and the technology used, Pokhara LFS had high technology with very good treatment for the leachate water and also a facility for composting organic matter. Nevertheless, the facility for composting was not in use, hence no separation of organic matter took place. According to [17], the lack of manpower was the main reason for its closure. The PSMC simply cannot afford operating the LFS properly. In Ghorahi Municipality and Karaute Danda Sanitary LFS, the operation was in small scale and the technology quite simple but still operational for its purpose. At Sisdole LFS, KMC, the technology was quite high with many systems installed but given the fact that the LFS was managed above its operational limits, the MSW was not deposited properly.

\section{CONCLUSIONS AND RECOMMENDATIONS}

\subsection{Conclusions}

Currently, the MSW generation per capita and day is quite low compared to Sweden and the EU. Nevertheless, because of rapid population growth and high urbanisation rate in Nepal, problems connected to MSW management will increase rapidly. MSW problems are furthermore interconnected with human health and water supply, and therefore are issues needed to be dealt with. However, the instability of the country tends to put aside focus from these serious problems.

Ghorahi Municipality has a well functioning MSW management system both in regards to the population and the size of the LFS. They have already adopted a consequent door-to-door collection system available for all urban dwellers. Therefore, in Ghorahi Municipality, new forms of MSW management and large scale in situ tests could be done; e.g. separation at source of domestic MSW and establishment of composting facilities. In regards to whether to include the rural areas of Ghorahi Municipality in the collection system or not, we have not been able retrieve enough data proving that the MSW generated in these areas are as diverse in composition as are MSW from urban areas. Therefore, prior to an incorporation of these rural wards in the collection system, further studies must be conducted. Currently, it might be more profitable to use the organic fraction of the MSW generated in the rural wards directly as fertilisers, thus preventing contamination of valuable MSW at the LFS. In PSMC, stricter demands on commercial institutions must be set in terms of how they manage their MSW. Perhaps the authorities should implement separation at source at least for all restaurants, hotels and other commercial institutions. This would facilitate an easier handling of valuable 
MSW for the scrap dealers as well as make it possible to actually use the composting facility at Pokhara LFS. In a longer term, all residents of PSMC should be included.

One of the biggest problems in KMC is the extremely high amount of waste coming to Sisdole LFS, where proper management certainly is lacking. The collection system is partly based on sweeping the roads, hence people are actually encouraged to deposit their waste on the roads. Furthermore, since there is no rigid MSW management people tend to deposit their waste wherever they think suitable, including on the riverbanks or in the rivers. A better and more consequent collection system is needed. This phenomenon also applies for PSMC. These issues must be dealt with prior to an implementation of a MSW system where the household and commercial waste is sorted at source.

We believe one main issue that needs to be dealt with is the attitude and behavioural issue. Even though many people seem to be aware of problems inadequate MSW management do cause, they still just do not care. In order to facilitate better behaviour and attitude, we believe the authorities must provide its citizens with easily managed, available and consequent solutions for the MSW management in the country. E.g. fewer collection systems instead of many different are to prefer. But currently, the lack of infrastructure hardens the collection of MSW in many parts of the cities. It is therefore of interest to obtain information which system is the suitable for which region, area and part of the city.

The urban areas of Nepal need to deal with MSW problems in accordance with the EU waste hierarchy. Even though the economic incentives encourage for re-use and re-cycling, currently a huge amount of the MSW generated still is deposited on LFS. If the fraction currently ending up at LFS instead could be recovered for energy, either by incineration or biogas generation, the issues directly connected to LFS could decrease. MSW needs to be looked upon as an asset instead of a cost.

Currently, there are slim indications that MSW sorting at source is feasible in all urban areas. However, in the near future energy recovery schemes could be feasible if the organic fraction can be sorted and collected in a proper way. This scheme should include both households and commercial businesses. As a suggestion, a presumptive implementation of such a scheme could initially include only one sector in a limited geographical area. Another option to maintain the value of the organic fraction in the urban areas is to provide citizens with chances to compost their food waste. Pokhara LFS has the facility needed for such a MSW management but the MSW currently generated in PSMC is too mixed.

There are no adequate regulations applied on MSW management at household level mostly due the the political turbulence that Neapl is facing. We believe that it is of great importance to include strict laws and guidance concerning MSW management in future national regulations. In the future, a collection fee as applied in PSMC, is preferable in all urban areas of Nepal. But there must exist incentives for people to be willing to pay and not just deposit their waste in a nearby river instead. Adequate regulations with appropriate sanctions could be incentive enough. Further studies on what appropriate sanctions are in Nepal are of importance in order to attain the right level. Even though sanctions were to be introduced the very poor will not be able to pay for the collection of their waste.

Furthermore, in Nepal it is mostly low cast people that deal with the waste. Waste pickers, scavengers, must be more appreciated by others for their hard work. Create a good working atmosphere with higher salary and insurance deals etc. and hence give incentives for people to work with the MSW. New established businesses and industries that can handle recyclables and reusables could be an alternative in Nepal and especially in urban areas. Now, there is a flow of these materials and thus monetary leakages to India. Nepal would gain much in establishing a more comprehensive industry regarding recyclable and reusable MSW with both a good working market and facilities. If the government of Nepal was to build facilities 
that could recycle paper, metal, plastics and glass; the market could appear automatically. Further studies in this field would be recommended.

The authorities of KMC, LSMC, PSMC and Ghorahi Municipality need to evaluate available alternatives to depositing on LFS. Incineration and biogas production could be feasible alternatives. In addition, biogas currently generated on the LFS could be a valuable energy source to collect. There will be a need of future studies on quantities and quality of the biogas prior to an execution of construction. Regardless of method and implementations, knowledge regarding maintenance of these systems must be secured and continuously communicated within the specific project and moreover within the country of Nepal.

\subsection{Recommendations}

- Stricter regulations with strict sanctions must be implemented and the responsibility of these new regulations must be distinctively delegated among the authorities. Furthermore, prior to an implementation, national external communication to concerned citizens is needed.

- There must be set stricter regulations on the current scrap dealer business after which the recycling business of Nepal must be further established in order to keep the value of the recyclables and thus the job opportunities within the country.

- Create a good working atmosphere with higher salary and insurance deals for people working with MSW, hence facilitate a shift towards more awareness of the importance of an environmentally sound and efficient MSW management.

- Investigations on possibilities for future energy recovery schemes, either incineration or biogas generation, needs to be further looked upon and developed.

- Further studies regarding social behavioural patterns and attitudes towards environmental and health problems connected to MSW, also needs to be conducted.

- Problems concerning improper handling and lack of management, connected to medical and hazardous waste, needs to be studied.

- Nepal needs to establish a national industry of material and energy recovery from MSW in order to reduce monetary leakage to India and China, and provide its citizens with job opportunities.

- There is need of a more coherent and consequent collection system, especially in KMC and PSMC. Further studies on what or which systems are best suited, and how these can be even more efficient, are needed. Studies are needed in order to retrieve the right level of collection fees and sanctions. The collection fee should not give incentives to deposit the MSW wherever, but instead to participate in the system.

\section{REFERENCES}

[1] Adhikari, B., Ghimire, A., Khanal, P., Rana, R, Sapkota L. \& Thapa, B. 2009. Composition Survey of Municipal Solid Waste of Kathmandu Metropolitan City (KMC).

[2] Avfall Sverige. 2009. Swedish Waste Management 2009. http://www.avfallsverige.se/se/netset/files3/web/P01.m4n?download=true\&id=3200 91 $\underline{983245}$ (Retrieved December 14, 2009) 
[3] Biegl, P., Salhofer, S., Schneider, F. \& Wassermann, G. 2004. Forecasting Municipal Solid Waste Generation in Major European Cities. Institute of Waste Management, University of Natural Resources and Applied Life Sciences, Vienna, Austria.

[4] Dutt A.K., Noble A.G., Subbiah S. \& Venugopal G. 2004. Challenges to Asian Urbanization in the $21^{\text {st }}$ Century. Dordrecht: Springer Science + Business Media, Inc.

[5] European Commission (EC). 2003. Preparing a Waste Management Plan - A methodological guidance note. http://ec.europa.eu/environment/waste/plans/pdf/wasteguide final.pdf $\quad$ (Retrieved December 14, 2009)

[6] European Commission (EC). 2008. Directive 2008/98/EC.

[7] Institute European Environmental Policy (IEEP). 2009. A Report on the Implementation of Directive 75/442/EEC on Waste.

[8] Khanal, B. 2007. Baseline information on Solid Waste Management of Tribhuwannagar Municipality of Nepal.

[9] Khanal, P., Sapkota, L. \& Thapa, B. 2009. Waste management and leachate treatment at landfill sites of Nepal.

[10] Larsson, G. \& Sahlén, J. 2010. Municipal solid waste management in Nepal, Sweden and EU - a case study of Ghorahi Municipality, Pokhara Sub-metropolitan City and Kathmandu Metropolitan City, Nepal. Bachelor Thesis, Lund Unversity/Kristianstad University.

[11] Manandhar, Dinesh Raj. 2009. Interview. Managing Director, Development Network Pvt Ltd. (Performed June 17, 2009)

[12] McCauley-Bell, P., Reinhart D. R. 1996. Methodology for Conducting Composition Study for Discarded Solid Waste.

[13] Pokhrel D. \& Viraraghavan T. 2005. Municipal solid waste management in Nepal: practices and challenges. Waste Management, 25, 555-562

[14] Prasad Luitel, Kishor. 2008a. Power Point Presentation on Study on Market Waste in Kathmandu Valley. (Performed May 20, 2009)

[15] Prasad Luitel, Kishor. 2008b. Study on the Recyclable and Reusable Non- BioDegradable Waste in Kathmandu Valley.

[16] Regmi, Subodh. 2009. Interview. Environmental Officer, Karute Danda Sanitary Landfill Site, Ghorahi Municipality. (Performed May 18, 2009)

[17] Resham G.C. 2009. Interview. Assistant Supervisor, Pokhara Sub-metropolitan landfill site. (Performed May 30, 2009) 